\title{
Esboço de uma compreensão da circulação de ideias: orientações para um estudo das modas educacionais*
}

Luiz Artur Santos Cestari

* Uma versão mais simplificada, e que apresenta pressupostos semelhantes aos deste artigo, foi socializada como comunicação, intitulada "Os modismos, a circulação de ideias e a formação de professores no Brasil", no Encontro Dialógico Transdisciplinar (Enditrans) realizado na Universidade Estadual do Sudoeste da Bahia (Uesb) campus Vitória da Conquista de 24 a 25 de novembro de 2010 .

\section{Resumo}

Este texto parte do anúncio da ocorrência de modismos no campo educacional e tem a intenção de estudar como uma ideia circula e se torna mais efetiva nos espaços de disseminação do conhecimento - revistas de divulgação científica, programas dos cursos de formação de educadores, propostas de políticas públicas para a educação ou ainda dissertações e teses publicadas em cursos de pós-graduação. Apresentamos nosso esboço em dois momentos. Inicialmente, tomados pela afirmação de alguns intelectuais no campo educacional, tentaremos expor por que eles anunciam os modismos, mas têm receio de incluir o fenômeno da moda de ideias no domínio de suas percepções. Posteriormente, indo além da constatação desse fenômeno, delimitaremos orientações para estudar a circulação de ideias no campo educacional e, particularmente, dos modismos educacionais, levando em consideração três contextos: emergência, recepção e disseminação.

Palavras-chave: circulação de ideias; modas educacionais; disseminação. 


\section{Abstract \\ Outlining an understanding of the circulation of ideas: guidelines for a study of educational fads}

This work starts from the announcement of fads in the educational field and intends to study how an idea circulates and becomes more effective in a particular locus of knowledge dissemination, such as journals of scientific dissemination, programs of training courses for educators, public policy proposals for education, or even dissertations and theses published in post-graduation courses. Then, an outline is presented in two moments. First, we call attention to intellectuals' assertions in the educational field, in order to expose why they announce fads, but fear to include the fashion phenomenon of ideas under the dominion of their perceptions. Then, we set guidelines in order to study the circulation of ideas in the educational field and, particularly, the educational fads, taking into consideration three contexts: emergency, reception and dissemination.

Keywords: circulation of ideas; educational fads; dissemination.

\section{Introdução}

Temos apresentado ao campo educacional uma preocupação relacionada ao modo como as ideias circulam e, em específico, a de tentar entender a acusação frequente nesse campo de que uma ideia esteja em moda. Compreender os modismos envolve apresentar as razões pelas quais uma ideia se torna mais importante que outra numa determinada época e por que ela se difunde, passando a ocupar o centro das preocupações de educadores e pesquisadores num certo momento.

O que nos permite perceber o fenômeno da moda é de imediato a repetição, ou seja, o anúncio dos mesmos pressupostos de forma repetitiva em espaços de disseminação - revistas de divulgação científica, programas dos cursos de formação de educadores, propostas de políticas públicas para a educação ou ainda dissertações e teses publicadas em cursos de pós-graduação. Assim, é pela repetição da ideia que nos convencemos da ocorrência dos modismos.

Por outro lado, nem sempre a repetição se dá pelas mesmas razões de apropriação de uma ideia, pois ao lado da repetição ocorre a diferenciação do modo como esta ideia será assimilada num contexto epistemológico. Como exemplo disso, temos o estudo que realizamos recentemente sobre a circulação das abordagens autobiográficas na formação de professores no Brasil. Naquele momento, tínhamos apontado que a repetição da "crença autobiográfica"1 era realizada em diversos domínios de estudos sobre formação de professores, isto é, em estudos sobre as didáticas

\footnotetext{
${ }^{1}$ Interpretação do núcleo comum de questionamento sobre si e o relato de experiências positivas e afirmativas dos sujeitos, ou seja, parte-se do pressuposto que a experiência autobiográfica é necessariamente afirmativa para os sujeitos. Ver Josso (2004), Pineau (2006) e Dominicé (2006).
} 
específicas - linguagem, matemática, ciências da natureza e sociedade; em estudos envolvendo preocupações identitárias, tais como os problemas relacionados ao gênero e à afrodescendência; em estudos sobre a inclusão social; etc. Desse modo, percebemos a ocorrência de sujeitos, em variadas situações formativas, questionando-se sobre sua vida e contando suas experiências formativas.

Diante disso, temos duas questões: Por que uma ideia se torna mais importante que outra, num determinado momento? O que faz uma ideia ser facilmente difundida num campo científico? Visando respondê-las, este texto será apresentado em dois momentos. De início, discutiremos algumas razões para estudar os modismos, sistematizadas considerando o seguinte paradoxo: os intelectuais anunciam os modismos na educação, mas tem "receio epistemológico" para incluir esse fenômeno no domínio de seus estudos. O anúncio desse paradoxo surge da identificação da percepção dos modismos de alguns intelectuais no campo da educação, pois, ao mesmo tempo que eles se sentem incomodados com os modismos, isso não se tornou motivação suficiente para realizarem um estudo desse fenômeno. Assim, o que percebemos nos autores, quando se referem aos modismos, são sentimentos que variam entre a lamentação, o menosprezo ou até a indignação.

Em seguida, buscando superar esse receio e assumindo o posicionamento de que o estudo dos modismos exige uma compreensão da forma como as ideias circulam pelo campo, elaboramos um esboço com base em três contextos: emergência, recepção e disseminação, ou seja, como uma ideia circula de um contexto histórico e epistemológico (contexto da emergência), migra para e é recepcionado em outro contexto (contexto da recepção) e, consequentemente, é difundida (contexto da disseminação) como uma moda num domínio específico, em nosso caso, no campo da formação de professores no Brasil.

\section{Modas educacionais: para além do receio epistemológico}

Há um bom tempo, convivemos no campo educacional com a afirmação, e em alguns casos isso se faz com inquietações, de que alguma ideia está em moda. A ocorrência disso tem sido feita pela repercussão de uma abordagem ao influenciar os discursos educacionais numa época e é possível que encontremos recorrência de uma mesma ideia em propostas formativas, no modo de falar dos docentes, em políticas públicas, em revistas científicas, em anais de congresso, etc. Assim, quanto mais notamos sua veiculação pelos espaços de disseminação do conhecimento, ainda mais nos damos conta de que se trata de uma ideia em moda.

Entretanto, a mesma convicção que temos em reconhecer a ocorrência desse fenômeno no campo não se mantém quando tentamos compreendê-lo, ou seja, admitir questões sobre o que é uma moda de ideia ou o que é uma ideia em moda não é uma opção tão comum quanto à de reconhecer os modismos. Por exemplo, em outro trabalho temos mostrado 
as contribuições de alguns autores brasileiros que aceitaram a tarefa de questionar o "construtivismo" como uma moda no campo educacional, e em nenhum deles foi encontrada qualquer elaboração conceitual da noção de moda. Além disso, quando notamos uma ocorrência, ela não é feita com a intenção de estudar a ideia como uma moda, mas se restringe a descrever um mínimo conceito para em seguida abandoná-lo. ${ }^{2}$

Nesses estudos, encontramos antes algumas percepções importantes quando se trata da ocorrência dos modismos de ideia na educação. A concepção mais comum da noção de moda de uma ideia é aquela que considera os modismos como resultado de uma adesão gregária, decorrente de uma apropriação inconsistente pelo professor (Arroyo 1993; Silva, 1993). Nesse sentido, identificamos que o docente é acusado de não obter o amadurecimento intelectual que seja comparável ao que fazem os intelectuais em suas experiências de pesquisa e, tendo em vista os precários processos formativos aos quais muitos são submetidos, eles são acusados de estabelecerem uma relação com a ideia que em muito se distancia do modo como esta é elaborada nos domínios de sua reflexão epistemológica. Devido a isso, encontramos estudos que acusam os processos rápidos e momentâneos de "formação continuada" de serem responsáveis por introduzirem, de modo também gregário, concepções desenvolvidas prioritariamente nos âmbitos das pesquisas acadêmicas. ${ }^{3}$

Essa primeira percepção da moda se constitui tomando como base a desvalorização do professor, até porque a distinção (professor x pesquisador) beneficia bem mais o campo intelectual, omitindo alguns problemas que os intelectuais teriam que justificar, tal como o receio em introduzir o conceito de moda no domínio de suas categorias de pensamento, uma vez que, ao fazerem isso, teriam que reformular suas perspectivas teóricas que tradicionalmente não contemplam o fenômeno da moda. Assim, a acusação de apropriação inconsistente parece ser uma saída fácil que livra alguns intelectuais de relutar frente às suas próprias construções e, em nosso ver, tão inconsistente quanto à atitude gregária a que acusam.

Outra concepção que encontramos na literatura no campo educacional é o entendimento de que os modismos são "ilusões da sociedade do conhecimento" (Duarte, 2005; Rossler, 2005). Nessa concepção, percebemos que as ideias em moda são falsas representações erigidas para justificar o novo ideário burguês ou esconder as contradições do capitalismo contemporâneo. Em nosso ver, essa concepção é problemática ao menos em dois pontos. Primeiro, porque sustenta a ideia de que há uma verdadeira representação da realidade e, logo, uma ideia que é mais verdadeira que aquelas submetidas ao efeito das modas. Nesse caso, a acusação de modismo se faz para mostrar que ainda há uma verdade utópica a qual nem todos estão intencionados a ver e que o professor se torna afeito ao modismo por ainda não ter adquirido a consciência adequada, por isso ele se ilude com as novas investidas do capital no campo educacional. Segundo, porque, ao manter a crítica ao capitalismo, os autores mencionados reduzem os modismos a uma espécie de

\footnotetext{
${ }^{2}$ Em Rossler (2005), os modismos nas sociedades modernas capitalistas são, no sentido de Agnes Heller, fenômenos de alienação. Ele afirma que o objetivo do seu texto "não é propriamente o de caracterizar o que seja um modismo e, especialmente, um modismo em educação, mas sim o de, adotando como pressuposto o fato de o construtivismo terse constituído num modismo, procurar analisar as origens sociais e psicológicas do poder de atração desse ideário" (Rossler, 2005, p. 5).

${ }^{3}$ No caso do construtivismo, por exemplo, a tradução do seu ideário para a prática de docentes em muitos casos não tem sido feita mediante uma reflexão sobre as condições diferenciadas entre o laboratório dos pesquisadores no domínio da psicologia cognitiva e a realidade escolar, onde os professores desenvolvem seu trabalho. Ainda notamos, nos dias atuais, pouca problematização da migração dessas ideias entre domínios epistemológicos e práticos distintos.
} 
(epi)fenômeno ideológico igualmente a outros que são inerentes à estrutura da sociedade capitalista, e é por esse motivo que uma postura dessa natureza olha bem mais para o instrumental crítico ao sistema capitalista do que para um fenômeno particular ao campo educacional, tentando estender a este a mesma crítica feita a outros objetos.

Uma terceira concepção que encontramos se nega desde o início a aceitar a moda como um fenômeno que merece atenção do campo educacional (Corazza, 1996). Por isso, faz uma incursão inversa às anteriores, pois rejeita qualquer construção interpretativa tomando como base uma distinção que atribui a alguns o privilégio do recuo crítico e a outros não, ou seja, não há um "grupo" responsável pelos modismos, mas este é um fenômeno do campo. Apesar disso, essa concepção se recusa em tentar problematizar a moda como uma categoria compreensiva, da mesma forma como fazem as outras concepções relatadas. Assim, esse posicionamento reconhece o fenômeno da moda, mas este é um fenômeno para o qual deveremos resguardar nossas ressalvas, e incluí-lo no conjunto de nossas preocupações seria perda de tempo.

O levantamento que aqui apontamos não é exaustivo, mas nos apresenta algumas indicações que permitiram nossa trajetória na relação com o tema. Em primeiro lugar, nenhum dos autores mencionados, e que se posicionaram frente ao fenômeno dos modismos no campo educacional, apontou para questionamentos sobre o que é uma moda, o que é uma moda de ideias ou quais são as particularidades desse fenômeno no campo educacional. Ao ler os trabalhos, percebemos o que denominamos de "receio epistemológico" em incluir a moda na ordem de preocupação do campo, e esse receio parece ser sustentado por sentimentos de revolta, de decepção ou até de indignação diante da ocorrência dos modismos.

Em segundo lugar, esse diagnóstico nos fez reconhecer que não podemos apresentar o problema dos modismos sem uma estenografia conceitual da noção de moda. Somente o anúncio e o sentimento negativo frente à ocorrência do fenômeno não são suficientes; acreditamos que, para o estudo das ideias educacionais em moda, ou seja, para compreender os modismos na educação, precisamos superar o receio epistemológico e tentarmos compreender como as ideias circulam, o fenômeno da moda e as questões que este suscita.

A primeira questão se refere aos processos de legitimação intermediados pelas distinções num contexto da produção intelectual. Diferentemente do que temos visto, nossa posição se distancia da acusação de que há um grupo de não iniciados responsáveis pela difusão das ideias como uma moda. Nossa argumentação visualiza que essa acusação é uma postura (pré)conceituosa, uma vez que não avalia o modo como circulam as ideias e como se dão suas formas de apropriação e recepção em contextos diferenciados. Por isso, tentaremos mostrar que as modas resultam da forma como as ideias circulam, mas, ao mesmo tempo, envolvem a legitimação de interesses no campo intelectual. Assim, não rejeitamos que há apropriação inconsistente num modismo, mas também não queremos correr o risco de isentar os intelectuais de seus ganhos na repercussão de uma ideia. 
A segunda questão se relaciona àquilo que é próprio desse fenômeno: sua contradição inerente. Procurando entender como teóricos sociais da moda apreenderam esse fenômeno - o que nos fez percorrer por autores como Simmel, Bourdieu, Lipovetsky, Tarde e outros -, identificamos nos estudos realizados, embora ressalvando suas particularidades, que todos esses autores faziam referência a um paradoxo inerente ao processo moda, ou seja, a moda é a ocorrência da repetição e da originalidade, pois, ao mesmo tempo que tenta imitar o mesmo, tem, também, a pretensão contínua de diferenciação. Foi esta estrutura que fomos tentar apreender nos estudos sobre modismos no campo educacional: o que se repete e o que se diferencia na ocorrência de uma ideia em uma moda?

A melhor contribuição teórica foi encontrada na obra de Gabriel Tarde, pois ele foi o primeiro autor que conseguiu teorizar a moda para além das aparências frívolas e a ter dado uma dignidade conceitual ao assunto, reconhecendo nela uma lógica e um tempo social específicos. $\mathrm{Na}$ elaboração tardiana de uma teoria da imitação, percebemos nos processos de imitação (imitação-costume, imitação-moda) a diferença e a repetição, uma vez que os exemplos descritos por Tarde eram processos ao mesmo tempo de continuidade e diferenciação.

Tentamos apreender isso ao estudar a difusão da "crença autobiográfica" na formação de professores no Brasil e, com isso, pudemos perceber como circula um discurso com forte apelo à defesa das experiências individuais e, ao mesmo tempo, levando em consideração a aceitabilidade irrestrita dos pressupostos do Movimento Pesquisa/ Formação, ${ }^{4}$ apostando bem mais nos efeitos de unicidade - aceitabilidade incontestável da crença autobiográfica - do que na valorização das diferentes experiências que tanto anuncia. Gabriel Tarde, nesse caso, foi de suma importância para que pudéssemos apresentar uma compreensão da circulação de ideias, o que tentaremos mostrar nas próximas nas sessões deste texto.

\section{Esboço de uma compreensão da circulação de ideias educacionais}

\section{Por que algumas ideias são mais importantes que outras?}

A sensibilização de uma ideia em relação às significações sociais de uma época parece ser aspecto importante para fornecer algumas indicações para que uma ideia se torne mais importante que outra. Visando dar conta disso, buscamos em Lipovetsky (1989) o argumento de que o "Império da Moda" anda ao lado da personalização dos indivíduos e, consequentemente, é por isso que as lógicas das novidades atingem os discursos de sentido e, de forma semelhante, o efeito de moda, comum aos objetos de consumo e da cultura, tem chegado às esferas consideradas até então mais refratárias, fazendo as ideologias circularem segundo a lógica da moda.

\footnotetext{
4 Nos últimos 20 anos na Europa, as autobiografias e/ ou as histórias de vida têm sido apropriadas pelo campo da educação com o sentido de uma experiência teóricometodológica de construção existencial, valorizando a vida e a experiência no processo de pesquisa enquanto formação de uma experiência existencial. Ver Pineau (2006), Josso (2004) e outros autores que têm denominado esse Movimento de Pesquisa/Formação.
} 
Entretanto, façamos logo um contraponto que o próprio Lipovetsky não deixa esquecer. É importante esclarecer que o "processo frívolo" não consegue se anexar inteiramente à vida das ideias e que as reviravoltas ideológicas sejam comandadas por uma lógica da inovação gratuita. Ele explica que chegamos ao momento em que as ideologias se reciclam na órbita moda e não naquele em que todas as ideias se sujeitam à moda, como se fosse possível falar num processo de moda em que as ideias flutuassem numa total indiferença.

Lipovetsky ainda afirma que as ideias sob a orientação da moda consumada só são possíveis numa sociedade na qual os valores edificantes da ideologia moderna se estabelecem consensualmente, isto é, em que os valores de igualdade e liberdade e os direitos do homem como base ideológica de fundo fixam os princípios da ideologia individualista. Essas condições das sociedades contemporâneas, segundo o autor, permitem a inconstância nos discursos, as pequenas variações individuais, seguidas da pacificação e da neutralização dos antagonismos.

Essa argumentação encontra respaldo em Tarde (2001), ${ }^{5}$ ao apresentar as formas de imitação social, especificamente quando ele se questiona: "Por que algumas ideias se tornam mais importantes que outras numa época?". Com essa pergunta ele vai mostrando que a difusão das imitações exige um tipo de disposição mais abrangente que influencia na adesão e nas escolhas das imitações mais importantes. Nesse sentido, Tarde (2001, p. 199, tradução nossa) ${ }^{6}$ apresenta a seguinte indagação:

... Por que, entre cem inovações diversas e simultaneamente imaginadas - quer se trate das formas verbais, das ideias mitológicas ou dos procedimentos industriais e outros -, há dez que se difundem no público, assim como seus autores, e noventa que permanecem no esquecimento?

${ }^{5}$ Destacamos aqui que a relevância atribuída aos estudos sobre a imitação em Gabriel Tarde para compreender as sociedades contemporâneas é apresentada pelo próprio Lipovetsky (1989).

${ }^{6}$...Porquoi, parmi cent innovations diverses simultanéament imaginnés, - qu'il sagisse de formes verbales, d'idées mythologiques, ou de procédés industriels et autres, - y en a-t-il dix qui se répandent dans le public à l'exemple de leurs auteurs, et quatre-vingt-dix qui rest dans l'oubli ?
Com essa problemática, o autor compreende que a imitação está submetida ao que denomina de motivação lógica ou teleológica, ou seja, é quando a inovação é escolhida e levada à propagação por seu caráter intrínseco, por julgá-la mais útil do que as outras, relacionadas às questões do seu tempo e submetidas aos fins e princípios nele estabelecidos.

Essa consideração nos levou a perceber duas condições relevantes para a análise da circulação das autobiografias nos tempos recentes. Primeiro não podemos esquecer a interpretação de Lipovetsky da valorização da individualidade na sociedade contemporânea. Tal como temos visto nos últimos anos, a literatura em diversos campos do saber nos tem apresentado o argumento da crise do modelo moderno de racionalidade global e, como contraponto a este, ela nos fornece a interpretação de que as sociedades contemporâneas se orientam por uma miríade de racionalidades ou, como afirma Santos (1996), ao notar que a crise da modernidade envolve um processo de reelaboração da concepção de subjetividade pela qual reivindicações modernas, orientadas pela emancipação da razão, dão lugar a novas reivindicações 
pautadas por formas diversificadas de racionalidade. Além disso, essa configuração enseja também o debate nas ciências humanas sobre as novas formas de identidades, orientado pela argumentação de que as formas de identificação numa condição dita pós-moderna são marcadas por negociações mais flexíveis (Hall, 1998).

Em Lipovetsky (1989), a individualização está associada a um processo mais amplo nas sociedades contemporâneas de despadronização sem precedentes da vida coletiva. Para ele, os sujeitos já não lamentam a perda contínua da subjetividade, uma vez que isso não os leva ao sofrimento.

Especificamente no campo da formação de professores no Brasil, a expressão de valorização da individualidade é encontrada naquilo que alguns autores denominaram de "reivindicação da subjetividade". Tomando como base uma breve revisão realizada nesse campo, ${ }^{7}$ percebemos que a repercussão das autobiografias vai encontrar um contexto favorável a sua circulação tendo em vista duas exigências postas à individualização dos sujeitos.

Uma delas é marcada pelo forte discurso de responsabilização do professor no âmbito das políticas educacionais, pelo qual percebemos como condição para a melhoria da qualidade do ensino a atuação individual do docente no contexto escolar, notado, por exemplo, com a aceitabilidade irrestrita das pedagogias das competências na formação de professores no Brasil e/ou com as políticas de incentivos mediante premiações à atuação individual de profissionais e unidades escolares.

A outra exigência é posta ao âmbito da produção intelectual. Uma das argumentações favoráveis à introdução das autobiografias para formação se justifica pela afirmação de um posicionamento contrário ao excesso dos discursos sobre a educação e a formação dirigidos ao professor. ${ }^{8}$ A reivindicação da voz do professor é um contraponto a esse discurso e, com isso, notamos, ao mesmo tempo, a valorização do cotidiano escolar e a construção pelo professor dos referenciais de suas teorias e práticas educacionais, tendo como centralidade sua própria vida.

Portanto, um cenário composto pelo esgotamento dos discursos no campo educacional e que incentiva uma busca incessante pelos sujeitos de sua individualidade parece ser um pano de fundo que enseja um contexto no qual a circulação de ideias é mais sensível às produções que tornam favoráveis as expressões desses sujeitos. Assim, nada mais útil para esse cenário do que uma concepção que solicita ao professor que busque as referências de sua formação nas próprias narrativas, pois às perguntas "por que uma ideia se torna mais importante que outra?" e "por que as autobiografias se tornam importantes para a formação de professores?" encontramos uma resposta adequada às exigências postas pelo nosso tempo e aos fins estabelecidos nele, ou seja, esse cenário prepara de certo modo as condições favoráveis à reivindicação da subjetividade no discurso sobre a formação do professor.

\footnotetext{
7 A respeito disso, ver Borges (2001), Nunes (2001) e Freitas (2002), que fazem uma boa revisão do cenário da produção intelectual na formação de professores nos anos 80 e 90, assim como Bueno (2002), que mostra que esse período é marcado pelo que denomina "reivindicação da subjetividade", no qual as produções se tornam mais sensíveis à expressão dos sujeitos.

${ }^{8}$ Sobre o excesso dos discursos dirigidos ao professor no campo educacional, ver Nóvoa (1999).
} 
Do superior ao inferior: a lógica da imitação-moda e a legitimação das ideias

Temos falado da moda de forma generalizada e, com certeza, muitas afirmações feitas sobre esse tema tomam como exemplo histórico as análises do objeto que tem sido seu referencial indispensável - que é a roupa. No entanto, mesmo um produto a se consagrar como uma moda propõe, indispensavelmente, um pacote discursivo como embalagem, a fim de que os clientes possam racionalizar suas preferências diante de fins imprecisos, instáveis e, às vezes, contraditórios, pois não se adere a uma moda apenas pela expressão visível que determinado objeto possa oferecer, mas por aquilo que o produto propõe ao sujeito, tal como o fato de consumir o objeto porque ele carrega o signo da novidade e/ou porque inclui determinado sujeito no conjunto daqueles que se diferenciam ou que ocupam posições diferenciadas na hierarquia do consumo.

De acordo com isso, mesmo em relação aos objetos de consumo, a moda se consagra pela adesão dos sujeitos a um discurso ou a uma ideia que tende a justificar suas escolhas funcionais. Alguns dos autores nas ciências humanas têm dado ênfase à segmentação do espaço social no consumo de um produto da moda, a qual tem sido apresentada pelo paradoxo entre a imitação e a distinção, ou seja, uma imitação com necessidade de originalidade que é resultado da rivalidade entre grupos.

Encontramos análises nesse sentido com as contribuições de Veblem (1983) e Simmel (1988), por exemplo, ao mostrarem que a significação ou a posição social que os objetos da moda forneciam ao seu possuidor resultavam num processo de seleção coletiva no qual o sucesso de determinados objetos - roupas, automóveis, cantores, métodos científicos, políticos, etc. - é fruto de uma construção coletiva mais ou menos organizada que reflete duas tendências da sociedade moderna: o peso da conformidade e o da diferenciação.

Outra contribuição foi a de Bourdieu (2006) quando analisou que os gostos e as opiniões de um grupo social são estabelecidos de acordo com um sistema de preferências que lhes é próprio. Os julgamentos e os comportamentos coletivos e a aceitação ou a rejeição de um objeto de moda são decorrentes dos habitus de cada um dos grupos representados, pois os objetos da moda fornecem aos grupos sociais um sistema de classificação que assegura, ao mesmo tempo, o reconhecimento interno de seus membros e a distinção comum em relação aos outros grupos. Assim, pode-se aceitar que, para Bourdieu (2006), a variação do gosto está associada, sobretudo, à das posições sociais.

Num primeiro momento, a análise de uma ideia em moda segue orientações semelhantes, entre elas a de examinar sua forma de legitimação, isto é, o que permite que uma ideia ganhe adesão e como ocorre sua difusão por parte de um grupo de profissionais num campo particular de produção do conhecimento, assegurando entre eles a 
distinção ao inserir-se como um membro que compartilha de uma mesma crença.

Ao lado desse processo, consideramos importante analisar, também, a função dos recém-chegados, expressa no que Bourdieu (2006) denomina de antinomia da sucessão. Para ele, os recém-chegados adquirem a capacidade de legitimar símbolos se eles tiverem vínculos estabelecidos com outros legitimadores mais antigos, obtendo, com eles, capital de autoridade e relações, até atingirem o poder exclusivo de constituir e impor símbolos de distinção legítimos.

Com esse objetivo, no estudo que realizamos recentemente sobre a circulação de ideias na educação, temos identificado os autores legitimadores no interior do campo da formação de professores e analisado seus posicionamentos na função de legitimar a ideia autobiográfica. Com isso, verificamos que a ação dos intelectuais como intermediadores de uma ideia num campo científico parece ser bastante significativa para desviar a atenção do campo para um conjunto de significados.

Como exemplo, temos as considerações que apontamos ao analisar as produções socializadas nos Congressos Internacionais de Pesquisa Autobiográfica (Cipa) realizados no Brasil. Nesses eventos, não foi difícil identificar nos autores, responsáveis pela introdução da ideia de formação pelas autobiografias, que a perspectiva do Movimento Pesquisa/ Formação já figurava em seus argumentos. Por isso, ao passo em que foram aumentando os trabalhos sob a influência desse movimento na realização das atividades de elevada distinção do evento, o que denominamos de "nível superior", do mesmo modo, também aconteceu em "nível inferior", quer dizer no conjunto das comunicações e de outros trabalhos socializados. ${ }^{9}$ Isso significa dizer que na organização dos eventos notamos que a constituição dos espaços de distinção passa imediatamente pela posição que ocupa a atividade diante das outras ações, pelo espaço destinado a essa atividade, assim como pelo tempo atribuído a cada autor para a socialização do trabalho.

No Cipa I, por exemplo, a influência do movimento era bem restrita em "nível superior" e, por esse motivo, os trabalhos de pesquisa expressavam senão o conjunto da própria diversidade das pesquisas no campo, pois dentre os trabalhos analisados, localizamos apenas um autor que foi responsável pelo anúncio dos pressupostos do Movimento Pesquisa/ Formação. Assim, da ausência de trabalhos em "nível inferior" resultava o isolamento desse movimento em "nível superior".

No Cipa II, a expressividade do movimento se dá de forma mais efetiva, e o principal organizador desse evento, quem bem o representou no primeiro, já tinha aceitado inconteste as influências dos pressupostos do Movimento Pesquisa/Formação. A repercussão disso em nível inferior foi o aumento da socialização de trabalhos nessa perspectiva. Não há uma relação direta entre a atuação dos organizadores desse evento e o aumento de produções em nível inferior, mas apenas podemos nos lançar pela hipótese de que a expectativa da realização do próximo evento e o trabalho, em conjunto com outros autores no campo educacional em

\footnotetext{
${ }_{9}$ A superioridade de alguns trabalhos (nível superior) que figuravam como conferências ou mesas introdutórias sobre temas orientadores do evento era socializada em espaços destinados a receber um grupo de pelo menos 200 pessoas e com um tempo de apresentação de no mínimo 30 minutos para cada trabalho. A grande maioria dos trabalhos (nível inferior) tinha 10 minutos para apresentação e discussão. Essa diferenciação marca a qualidade de inferior e superior na organização de uma atividade.
} 
diversas instituições, contribuíram para a consolidação dessa perspectiva, e isso se fez mediante a circulação de uma ideia nos processos formativos, pela atuação de grupos de pesquisas, assim como pela publicação em espaços de disseminação da literatura pedagógica. Além disso, vale a ressalva de que uma compreensão mais detalhada desse processo deve envolver um estudo da atuação dos grupos de pesquisas e de autores legitimadores não somente nos espaços dos eventos, mas também nas instituições das quais fazem parte.

No terceiro evento, da mesma forma, vimos que seu organizador principal, juntamente com outros autores, dá continuidade à expansão desse movimento e, para isso, são criadas novas formas de legitimação, pois pela primeira vez identificamos atividades ligadas a grupos de pesquisa sobre formação, já consolidados em programas de pós-graduação, e essa configuração cria novas condições para a disseminação porque, ao mesmo tempo que dá visibilidade aos grupos criados com a finalidade de realizarem estudos nessa perspectiva, atrai outras pesquisas para o centro do debate, permitindo a constituição de novas inter-relações no campo educacional.

Ao estudar a circulação das abordagens autobiográficas na formação de professores no Brasil, pudemos verificar que, ao buscarem a consolidação de um domínio de estudos no campo da formação, os autores tiveram que se apropriar dos pressupostos do Movimento Pesquisa/ Formação já disseminados na Europa desde os anos 80, mas também adquiriram, mediante a presença dos autores europeus nos eventos, a autoridade para constituir significados legítimos no campo da formação no Brasil. Tudo isso decorreu da presença marcante dos autores brasileiros nos eventos, coordenando as principais conferências, organizando e compondo as principais publicações, assim como orientando a criação de novas organizações para a consolidação desse movimento no Brasil. Além das vinculações institucionais, percebemos também nos autores brasileiros apropriação irrestrita do ideário desse movimento, uma vez que são bem presentes neles os fundamentos já apresentados pelos autores europeus.

Essa breve exposição nos levou a indicar a primeira consideração sobre a circulação das ideias em moda. De início, vale a ressalva de que nossos estudos ratificaram nosso posicionamento, o qual afirma que o modismo é um processo iniciado pela ação intelectual de negociar relações de autoridade e se estabelece de cima para baixo, tal como Tarde (2001) nos mostrou em uma das suas leis lógicas da imitação, ao apontar que esta desce necessariamente do superior ao inferior, ou seja, de início uma imitação se estabelece entre aqueles considerados superiores numa hierarquia e só depois ela mutualiza. Em nosso caso, a ideia é apropriada entre os reconhecidos intelectuais, ganha legitimação entre eles e depois é recepcionada entre os não iniciados.

A segunda consideração tardiana e que caracteriza o processo de imitação como uma imitação-moda refere-se à influência do estrangeiro, quer dizer, à consideração de que as imitações oriundas de outros locais sejam mais válidas e exerçam um poder de atração mais efetivo. O que 
acrescentamos com essa proposição de Tarde é o fato de que as ideias migradas do estrangeiro já são traduzidas e imitadas como superiores às imitações existentes. Isso não foi difícil encontrar, pois os autores estrangeiros vinculados ao Movimento Pesquisa/Formação sempre aparecem nos eventos organizados no Brasil em posições de elevado destaque, ao mesmo tempo que a percepção da aceitabilidade de suas ideias é bem mais expressiva que sua refutação.

\section{A circulação da ideia em três contextos: emergência, recepção e disseminação}

Mostramos na seção anterior que a análise de uma ideia em moda nos exige, inicialmente, um olhar para as formas de constituição de interesses. Esse primeiro momento já nos é suficiente para dizer que a moda de uma ideia tem um ponto de partida: permitir a alguns intelectuais instituírem significados legítimos num campo.

No entanto, esse tipo de análise apenas se atém a mostrar as formas de negociação para a adesão de uma ideia entre os intelectuais da educação, mas não é suficiente para justificar a sua difusão num campo de saber. Nesse sentido, indicamos uma análise da circulação da ideia autobiográfica para formação de professores no Brasil, considerando três contextos: contexto de emergência, compreendendo a origem da ideia, depois, como ela é apreendida no contexto da recepção e como ela se difunde no contexto da disseminação.

Algumas contribuições teóricas nos permitem esboçar o que estamos denominando, neste trabalho, de contexto de emergência. De início, a emergência de uma ideia acontece pelo fato de que algo novo surgiu e que precisamos dar conta dessa novidade. Kuhn (2005) reconheceu que existe uma dificuldade em distinguir um "fato" de uma "invenção teórica", ou seja, entre algo que passou a existir ou que passou a existir para nós naquele momento. A noção de emergência de uma ideia, um paradigma ou uma perspectiva vincula-se ao contexto que permitiu aos sujeitos se voltarem para um fato que ainda não teriam incluído no domínio de sua percepção.

O exemplo relatado por Kuhn da pesquisa sobre a experiência perceptiva com as cartas de baralho é notório. Ele menciona que num estudo realizado por Burner e Postman (apud Kuhn, 2005, p. 89) se solicitou que entrevistados identificassem uma série de cartas de baralho, as quais obedeciam a uma sequência e a um tempo de apresentação. Cartas alteradas foram introduzidas entre as de naipes de mesma cor e forma e, depois de muito tempo, os entrevistados perceberam as diferenças - isto é, até fazerem parte da forma de percepção das pessoas, as anomalias não eram identificadas.

Para Kuhn, tanto na ciência como na experiência com cartas de baralho a novidade emerge com dificuldade contra um pano de fundo fornecido pelas expectativas. De início, os sujeitos são levados pelo hábito e pelo que 
é previsto, até que a consciência da anomalia é inclusa nas expectativas e se converte em previsto (Kuhn, 2005, p. 91).

Do mesmo modo, em Foucault (1999) percebemos que a emergência dos saberes modernos nas ciências humanas foi possível pela forma como o homem aparecia, quer dizer, outro regime de positividades permitiu que o homem fosse abordado em determinado momento segundo a forma como a epistémê lhe deu lugar. O autor realiza uma crítica às condições de surgimento dos discursos no campo das ciências humanas, e uma das questões ressaltadas por ele relacionava-se à condição da linguagem, por meio da qual se tornam visíveis muitas positividades, mas também se ofuscam as condições de aparecimento dos saberes dos quais essas positividades são constitutivas.

Foucault coloca em As palavras e as coisas que a linguagem é a representação do saber, que já é uma representação, ou seja, o que é "visível" e o que é possível se tornar "dizível" em função das condições que permitem aos saberes se constituírem em positividades. Com o exemplo da taxionomia chinesa, ${ }^{10}$ o autor nos coloca frente àquilo que em nosso pensamento ocidental é recusado dizer. Na obra de Velásquez, as condições de visibilidade, criadas pela presença do autor na cena, demonstram a função estratégica dele como imanente à construção do saber: ele faz parte da configuração das positividades no interior de um campo.

Por fim, no outro exemplo, Dom Quixote de Cervantes, Foucault mostra o caráter da linguagem nas sociedades modernas, referindo-se à separação entre as palavras e as coisas, ao deslumbramento de Dom Quixote pelas palavras quando tenta encontrar territorialidade para os romances de cavalaria: onde estão as coisas referentes às minhas palavras?

Portanto, no exemplo em pauta, num contexto de emergência procuramos encontrar as justificativas que permitiram as autobiografias entrarem no âmbito da percepção dos pesquisadores de um campo, ou seja, quais condições possibilitaram incluir as autobiografias no regime de positividades do campo educacional e da formação de professores. As autobiografias, historicamente, aparecem de diversas formas e com particularidades em seu uso em cada campo de conhecimento ou numa obra de determinada época, e nesses muitos outros momentos elas não aparecem para o campo educacional do modo como sugere o

10 A citação da taxinomia da enciclopédia chinesa é uma referência que Foucault faz ao poema de Borges: "Esse texto cita certa enciclopédia chinesa onde será escrito que os animais se dividem em: a) pertencentes ao imperador, b) embalsamados, c) domesticados, d) leitões, e) sereias, f) fabulosos, g) cães em liberdade, h) incluídos na presente classificação, i) que se agitam como loucos, j) inumeráveis, k) desenhados com um pincel muito fino de pêlo de camelo, l) etc, m) que acabam de quebrar a bilha, n) que de longe parecem moscas". Movimento Pesquisa/Formação. Por isso, para a delimitação do contexto de emergência, deve-se questionar e buscar responder: Por que e por quais razões as autobiografias aparecem de forma tão significativa para a formação de professores naquele momento? O que permitiu à abordagem autobiográfica ocupar o lugar da percepção dos educadores para estes pensarem sua formação e sua ação educativa? Quais os sentidos atribuídos à vida e à formação no conjunto das reflexões desse movimento?

Assim, o contexto da emergência é aquele em que as respostas a essas perguntas permitem vincular a abordagem autobiográfica para a formação de professores ao Movimento Pesquisa/Formação iniciado na Europa nos anos 80. Nosso posicionamento assume que a emergência da crença autobiográfica para a formação de professores é o espaço aberto 
por esses pesquisadores que deu lugar epistemológico para se falar da vida de docentes ao tratar de sua formação.

O segundo contexto de nossa análise é o da recepção e tem aproximações com a noção de "campo de acolhida" ou da "recepção" em Bourdieu (1990). Nesse momento, nossa atenção esteve voltada para a migração da "crença autobiográfica" e como ela foi apropriada pelo campo da formação de professores no Brasil.

Parafraseando Bourdieu (1989), percebemos que a internacionalização de ideias é um processo que não se faz sem o risco de atribuir significados a obras e autores distantes do seu contexto de origem e, ao buscar compreender a migração da ideia de formação na recepção das abordagens autobiográficas para a formação de professores no Brasil, tentamos apreender suas formas de significação construídas no contexto da recepção. Partimos do pressuposto de que existe nesse contexto um conjunto de problemas e ideias que situam a discussão sobre a formação de professores no Brasil e que essa significação é uma construção histórica constituída nesse campo, no qual posições já estão determinadas e legitimadas quanto às formas de percepção e compreensão da formação. A entrada de uma nova perspectiva sugere que as legitimações das ideias venham dar espaço a novas posições e, com isso, alterar a lógica da dominação e da definição das formas de percepção no campo.

Portanto, a análise do contexto da recepção é a análise da recepção dessas abordagens no campo da formação de professores no Brasil e, para isso, identificamos as justificativas de apropriação mediante as produções que introduziram a abordagem do Movimento Pesquisa/ Formação ao debate da formação de professores no País. Diante disso, propomos elaborar um esboço das justificativas que levaram alguns intelectuais a problematizarem a vida dos professores para estudar sua formação e apontar as justificativas do vínculo dessas produções com o Movimento Pesquisa/Formação, quer dizer: delimitar como a abordagem autobiográfica, que emerge no campo da formação na Europa nos anos 80, é recepcionada no Brasil nos anos 90 no contexto da formação de professores.

Tomamos como pressuposto neste trabalho que as ideias, sujeitas à migração entre contextos, são condições para que se possam identificar os seus "modismos". Não se quer afirmar que toda ideia migrada será uma moda, mas apenas que a forma como elas se estabelecem no contexto da recepção é condição para que venham a se tornar uma moda.

Para isso, realizamos uma história social da problemática das autobiografias para a formação de professores no Brasil, apontando os sentidos delas para os estudos e as pesquisas nesse domínio. Nessa incursão, pudemos perceber que as ideias migradas de outros contextos tendem a circular pelo contexto da recepção como um modismo, porque os sentidos dessas ideias estão cada vez mais distantes daqueles identificados na história social do problema.

Por exemplo, tomando como base um estudo realizado com a literatura sobre formação de professores e o uso das abordagens autobiográficas, 
pudemos notar que se utilizaram as autobiografias para anunciar um problema específico do contexto da formação de professores no Brasil, ou seja, as pesquisas tentavam mostrar o problema do gênero, discutindo a feminização do magistério no País e as trajetórias de professoras em escolas públicas; a questão da afrodescendência e da inserção do negro nas escolas e nas universidades no Brasil; a questão da leitura e do acesso ao conhecimento, etc. Assim, o uso das autobiografias encontra justificativa nos problemas inerentes à educação e às escolas brasileiras.

De modo diferente, encontramos as autobiografias nos estudos influenciados pelo Movimento Pesquisa/Formação, no qual elas tiveram o interesse de (re)significação da vida dos sujeitos. Nesse movimento, os autores querem antes colocar os docentes para contar sua história visando a uma avaliação dos significados de suas vidas do que mostrar problemas que eles enfrentam no contexto das escolas e da sociedade brasileira. Essa mudança de enfoque no uso das autobiografias fez com que o ideário do movimento de valorização da experiência narrativa como processo de formação se afastasse cada vez mais dos problemas da formação vivenciados pelos professores no Brasil. Em muitos estudos, encontramos o uso das autobiografias justificado apenas na crença de que "contar sua história a si" revela sentidos ainda não percebidos, isto é, o uso das autobiografias se justifica pela potencialidade que tem essa experiência em oferecer situações para a constituição dos significados de uma vida.

O conflito gerado pela circulação dessas percepções distintas é interpretado, no horizonte do trabalho de Tarde (2001), quando ele afirma que a adesão a uma imitação ocorre quer seja por meio de uma substituição, envolvendo um "duelo lógico" (le duel logique) e a luta entre as duas alternativas, quer seja por meio de "acumulação" (I'accouplement logique), que é um processo ligado a uma união lógica de imitações. Para Tarde, a adoção de uma imitação só é possível pelo progresso, e as revoluções sociais são a causa deste. Ele esclarece que o progresso não tem cérebro próprio e que resulta da solidariedade "intermental" - em termos mais recentes na literatura, intersubjetivo - dos vários inventores que realizam troca de suas descobertas e invenções. Nesse caso, o pensamento individual continua a existir (afirmação da subjetividade), no entanto, tem-se como resultado uma permuta de descobertas mediante a comunicação intersubjetiva - o progresso social e o individual são, consequentemente, substituídos por meio dos duelos lógicos ou resultado da acumulação.

Tarde não economiza argumentos passando por diversos objetos para fazer entender suas leis lógicas da imitação. Em relação à linguística, assinala os duelos quando uma língua tenta se impor sobre um dialeto; quanto à religião, destaca os duelos religiosos entre o dogma oficial e o herético - trazendo como exemplo o conflito entre as religiões proselitistas e não proselitistas -; assinala os duelos jurídicos quando dá ênfase à luta para a aprovação de uma lei ou à luta no tribunal entre um autor e um demandado; destaca os duelos industriais entre uma invenção já 
estabelecida há algum tempo e as inovações que tendem a se espalhar; e evidencia os duelos artísticos quando uma escola afirma um gênero de beleza negado por outra escola.

Em relação às uniões lógicas (l'accouplement logique), nas quais se verifica a acumulação das invenções, Tarde nos traz o exemplo das línguas, das mais antigas organizações políticas, da religião e da ciência. Passando pelos exemplos, ele mostra o esforço lógico da imitação em unificar, acumulando as invenções. Nas línguas, percebe-se isso com a aquisição sucessiva de palavras, de formas verbais, que, exprimindo ainda ideias não expressas, não encontram qualquer rivalidade a vencer para se estabelecerem. O autor afirma, também, que o ideal seria que cada ciência fosse redutível, de modo que as diferentes fórmulas tivessem como ligação uma fórmula superior, ou seja, que houvesse ciência, e não ciências; entretanto, para Tarde, o processo de diferenciação não cessa e a diferenciação segue depois da acumulação.

É isso que acontece quando analisamos a difusão da "crença autobiográfica" no contexto que chamamos de disseminação, isto é, uniões seguidas de diferenciação. Nesse contexto, propomos estudar a ideia autobiográfica para a formação num aspecto que a caracteriza como um fenômeno de moda, que é o estudo da repetição de sua combinação com os problemas sobre a formação de professores no Brasil, isto é, identificando os sentidos das autobiografias para os estudos sobre os docentes. Nesse momento, interessou-nos localizar um espaço de disseminação específico para verificar as ocorrências de repetição e diferenciação dessa crença e, para tanto, escolhemos os Congressos Internacionais de Pesquisa Autobiográfica realizados no Brasil em 2004, 2006 e 2008, para difundir os pressupostos do Movimento Pesquisa/Formação.

Em todos os autores estudados, identificamos, ressalvando as especificidades do pensamento de cada um, a moda como um processo que é movido por um paradoxo: a repetição com necessidade de originalidade. Em Tarde, encontramos esse aspecto de forma mais aprofundada, pois há uma teoria de compreensão do processo de imitação e sua específica forma, que é a imitação-moda. Para apresentar argumentos que expliquem esse processo nas sociedades, Tarde faz uma crítica à repetição como similitude, própria ao procedimento de construção do saber moderno baseado em dados estatísticos.

De acordo com isso, Tarde defende o pressuposto de que repetição é diferente de similitude, aquilo que é repetido e realizado não é senão um fragmento do realizável e, diferentemente de pensar a repetição como similitude, ele a entende como uma imitação, que é uma multiplicação, na qual há processos de continuidade, mas também de diferenciação. Para esse autor, os fenômenos de imitação partem da diferenciação e seguem para a diferenciação, embora os processos de uniformização estejam no intermédio do inacabado processo de continuidade e diferenciação.

Um aspecto importante para a compreensão da ideia como moda, segundo orientações do pensamento de Tarde, é a definição do que considera como aspecto da imitação. Para ele, o que é imitado são 
crenças e desejos. Numa ideia, como em nosso exemplo, as crenças são pressuposições e os desejos são interpretados como intencionalidades. Quando o autor nos coloca frente a essa definição, põe-nos diante do entendimento de que a análise de uma ideia sob a moda é a dos pressupostos e das intencionalidades inscritas nela.

A forma de análise do efeito da moda passa pela análise das maneiras de repetição-diferenciação da ideia autobiográfica para a formação, mas também pela explicação de sua difusão. Eis aqui o aspecto mais característico da contribuição de Tarde, pois, dentre as teorias apontadas, muitas se preocupam com o aspecto inclusivo ou exclusivo dos sujeitos no acesso aos objetos sob moda, mas é ausente nelas uma compreensão das motivações pelas quais as ideias se difundem.

Desse modo, levando em consideração o argumento de Tarde, dedicamo-nos a compreender as formas de apropriação da "crença autobiográfica" - autoafirmação pelas narrativas de si - por estudos e pesquisas realizadas no campo da formação de professores. Em nossa análise, pudemos notar a circulação dessa mesma crença em diferentes conjuntos de interesses em pesquisas sobre a formação. Percebemos que o uso das autobiografias se faz em variadas situações de estudos, nas quais encontramos em comum a invariável questão sobre a construção de si.

Para exemplificar, em pesquisas sobre educação matemática, o professor começa a questionar as razões pelas quais se tornou docente dessa disciplina, quais as relações históricas ele estabeleceu com a matéria como aluno e se isso de certo modo altera a sua atuação como professor. Do mesmo modo, encontramos essa incursão em pesquisas sobre docentes de outros conhecimentos em domínios específicos das didáticas, em reflexões sobre temáticas pedagógicas, tal como a questão de problematizar as experiências de estágios de alunos mediante a história de suas vidas. Encontramos ainda pesquisas que tentam aproximar diferentes áreas de conhecimento pelas autobiografias, isto é, estudos envolvendo áreas da saúde e da educação, por exemplo, bem como pesquisas autobiográficas que apresentam a trajetória formativa de sujeitos em campos nos quais a problematização sobre os percursos da vida é quase inexistente, levando em consideração um histórico da produção desse campo. Também encontramos estudos socializados em eventos sobre pesquisas autobiográficas em que bibliotecários apresentavam questionamentos sobre a "construção de si" e a experiência formativa na sua trajetória como bibliotecário.

Assim, o que aproxima essas pesquisas é a circulação da "crença autobiográfica", ou seja, este é um elemento comum, que se repete entre os vários estudos apreciados em nossa pesquisa. Temos percebido que invariavelmente a "crença autobiográfica" é aceita como núcleo de questionamentos que permitem aos sujeitos indagarem suas vidas em variados domínios de estudos e pesquisas e apostarem, ao mesmo tempo, na crença de que há sempre um resultado afirmativo desse processo. Percebemos, também, que a circulação das ideias se faz pelo anúncio autojustificado dos pressupostos do Movimento Pesquisa/Formação, isto 
é, o uso dessa abordagem encontra em sua potencialidade significativa as razões de sua apropriação, deixando de lado as especificidades dos domínios das pesquisas e dos estudos em que são introduzidos.

Por fim, visualizamos com essas formas de apropriação da "crença autobiográfica" mais uma das condições, segundo Tarde, para a difusão de uma imitação como uma moda que é a ruptura com a tradição, interpretada em nossas pesquisas quando os autores se afastam da forma como os estudos vêm sendo realizados no campo da formação e, levados pela significação da novidade fornecida pelo Movimento Pesquisa/ Formação, começam a direcionar seus estudos segundo as orientações dessas perspectivas.

Segundo Tarde (2001), a superioridade pela qual um exemplo é preferido diante de outros trata da relação dos sujeitos com as influências que se originam em seus antepassados ou naqueles que lhes são contemporâneos, e isso justifica a formulação do autor da passagem do costume à moda, ou seja, do "tout antique, tout bon" ao "tout nouveau, tout beau", o que pressupõe, além disso, uma mudança na forma como a imitação se impõe aos sujeitos, no primeiro caso (imitação-costume) pela autoridade dos antepassados aos iniciados e, no segundo (imitaçãomoda), por persuasão: "... Verdadeiramente, é simplesmente e após a aceitabilidade cega das afirmações tradicionais que se impõe pela autoridade que a acolhida das ideias estrangeiras se impõe pela persuasão" (Tarde, 2001, p. 302). ${ }^{11}$

Além dessa ruptura com seus antepassados, os sujeitos submetidos à imitação-moda rompem também com as influências de sua localidade, e o efeito de moda no processo de imitação é uma junção das influências sobre os sujeitos que se fazem pela suposta superioridade do estrangeiro e do tempo presente sobre o tempo passado, como diz Tarde (2001, p. 304, tradução nossa): ${ }^{12}$

... Quando a história da família ou da cidade não é mais considerada venerável, por causa de uma razão mais forte, todo o passado deixou de existir e o presente parece dever inspirar o respeito, mas, pelo contrário, desde que seja suficiente serem pais ou compatriotas para se julgarem iguais, o estrangeiro sozinho, em geral, parece produzir a impressão amigável que dispõe a imitar. À época onde pressente o costume é mais influenciada pelo seu país que pelo seu costume, porque ventila, sobretudo, o tempo passado. As épocas em que predomina a moda tornam-se mais fiéis a seu tempo do que a seu país.

Para o autor, esse cominho que segue da imitação-costume à imitação-moda é uma alternância necessária e universal, pois chega a definir que, em diferentes épocas ou sociedades, as imitações variam entre os modelos oriundos da tradição e os atuais, do estrangeiro. Ele explica que a imitação-moda não confirma nem contradiz uma ideia já estabelecida pela tradição, mas o contato com o estrangeiro tem sido suficiente para certa curiosidade. Diante disso, afirma que as sociedades tradicionais, predominantemente rurais, recebem influências porque nos povos primitivos rurais permanece a imagem forte de sua infância, ainda

\footnotetext{
11 "...À vrai dire, c'est simplement, aprés l'acceptation aveugle des affirmations tradicionelles qui s'imposaintent par autorité, l'accueil fait aux idées étrangères que s'imposent par persuasion"

12 ...Quand le passé de la famille ou de la cité n'est plus julgé vénérable, à plus forte raison tout autre passé a-t-il cessé de l'être; et le présent seul semble devoir inspirer le respect ; mais, à l'inverse, dès lors qu'il suffit d'être parents ou compatriotes pour se juger égaux, l'etranger seul, em général, semble devoir produire l'impression respetuese qui dispose à imiter. - Aux époque où prévaut la coutume, on est plus infatué de son pays que de son temps, car on vante surtout le temps jadis. Aux âges où la mode domaine, on est plus fier, au contraire, de son temp que de son pays.
} 
sob a determinação paternal, enquanto aos adultos da vida urbana é permitido se modelar em acordo com tipos exteriores, abalando o equilíbrio costumeiro e restabelecendo como costume aquilo que se tornou moda: "... Mas este retorno final do espírito da moda ao espírito do costume não é de forma alguma um retorno" (Tarde, 2001, p. 306, tradução nossa). ${ }^{13}$

Por conseguinte, a vida social, nesse sentido, é um processo universal no qual há a alternância, inicialmente, da imitação-costume-imitação dos modelos antigos e autóctones - com a imitação-moda, caracterizada pela invasão das novidades estrangeiras que abalam o equilíbrio do costume e por uma temporalidade legítima, o presente social, para, em seguida, voltar a ser costume, variando do superior ao inferior.

\section{Considerações finais}

A primeira consideração de nosso trabalho visa apontar contribuições teóricas que deem conta de realizar uma interpretação dos modismos, distante do que temos identificado no campo educacional. Tal como relatamos, as modas são vistas seja como "apropriações inconsistentes", ou "ilusões", ou ainda um tipo de "degeneração" das ideias, cuja atenção dada seria perda de tempo. Discordamos desses posicionamentos e tentamos apreender o fenômeno da moda como um processo de apropriação e difusão das ideias que reflete o peso da conformidade e da diferenciação, ou seja, de unicidades, seguidas necessariamente pelas diferenciações.

Quanto à segunda consideração, queremos continuar mostrando que a disseminação de ideias pode propiciar efeitos de unicidade num campo científico, cuja finalidade é a eliminação da diferença e da pluralidade. No estudo sobre as abordagens autobiográficas na formação de professores no Brasil, apontamos que elas circularam pelo campo da formação marcado por um sentido introduzido pelo Movimento Pesquisa/Formação, cujo núcleo de consolidação dessa proposta estava na difusão do que denominamos de "crença autobiográfica", levando em consideração que as narrativas de vida encontradas no seio desse movimento eram sempre tomadas como valorações positivas, ou seja, contar sua história a si mesmo era sempre um processo de afirmação de si, considerado formativo.

Visualizamos em nosso trabalho que a aceitabilidade dessa concepção em domínios específicos no campo da formação se tornou o meio pelo qual os autores começavam a negociar a sua entrada nesse movimento, pois bastava os pesquisadores introduzirem questionamentos sobre a vida do autor, envolvendo os mais diversos problemas de pesquisa e universos teóricos, para fazer com que seu estudo adquirisse a condição de uma "pesquisa autobiográfica", ainda que as trajetórias de investigações

13 ... Mais ce retourn final de l'esprit de mode à l'esprit de coutume n'est nullement une rétrogradation". nesse domínio específico do campo da formação e dos próprios autores tivessem pouca ou quase nenhuma relação com as questões históricas ou autobiográficas. 
Conseguimos notar, ainda, que os Encontros Internacionais de Pesquisa Autobiográfica foram espaços de negociação da entrada de muitos autores nos estudos autobiográficos e, para isso, adotaram o núcleo de questionamentos da "crença autobiográfica" como linguagem necessária para se ter acesso ou até para figurar com posição de destaque na estrutura do evento. Desse modo, percebemos as autobiografias circulando pelo campo da formação, cuja pretensão foi a afirmação dessa perspectiva como uma metodologia adequada a variados domínios de estudos. Em nosso entendimento, essa pretensão é a expressão de uma intenção de unificar as diversas pesquisas por meio de uma única metodologia, uma pretensão de unicidade que vai ao encontro da negação da diferença e da pluralidade, que são contraditoriamente reiteradas no seio do Movimento Pesquisa/Formação.

\section{Referências bibliográficas}

ARROYO, Miguel. Construtivismo: teoria séria, moda preocupante. Revista da AMAE Educando, Belo Horizonte, n. 238, p. 13-15, set. 1993.

BORGES, Célia. Saberes docentes: diferentes tipologias de classificações de um campo de pesquisa. Educação \& Sociedade, Campinas, v. 23, n. 74, abr. 2001.

BOURDIEU, Pierre. Les conditions sociales de la circulations des idées. Cahiers d'Histoire des Literatures Romanes, v. 14, n. 1-2, p.1-10, 1990

BOURDIEU, Pierre. O costureiro e sua grife: contribuição para uma teoria da magia. In: . A produção da crença: contribuição para uma economia dos bens simbólicos. 3. ed. Porto Alegre, RS: Zouk, 2006.

BUENO, Belmira Oliveira. Histórias de vida e autobiografias na formação de professores e profissão docente (Brasil, 1985-2003). Educação e Pesquisa, São Paulo, v. 32, n. 2, p. 385-410, maio/ago. 2006.

CORAZZA, Sandra Maria. Construtivismo: evolução ou modismo? Educação \& Realidade, v. 21, n. 2, p. 215-232. jul./dez. 1996.

DELORY-MOMBERGER, Christine. Formação e socialização: os ateliês biográficos de projeto. Educação e Pesquisa, São Paulo, v. 32, n. 2, p. 359-371, maio/ago. 2006.

DOMINICÉ, Pierre. A formação de adultos confrontada pelo imperativo biográfico. Educação e Pesquisa, São Paulo, v. 32, n. 2, p. 345-357, maio/ago. 2006. 
DOMINICE, Pierre. L'histoire de vie comme processus de formation. Nouvelle édition Paris: L'Harmattan, 2002.

DUARTE, Newton (Org.). Sobre o construtivismo. 2. ed. Campinas, SP: Autores Associados, 2005.

DUARTE, Newton (Org.). As pedagogias do "aprender a aprender" e algumas ilusões da assim chamada sociedade do conhecimento. Revista Brasileira de Educação, São Paulo, n. 18, set./out./nov./dez. 2001. Disponível em: <http://www.scielo.br/pdf/rbedu/n18/n18a04.pdf>

FOUCAULT, Michel. As palavras e as coisas: uma arqueologia das ciências humanas. 8. ed. São Paulo: Martins Fontes, 1999.

FREITAS, Helena Costa Lopes de. Formação de professores no Brasil: 10 anos de embates de projetos de formação. Educação e Sociedade, Campinas, v. 23, n. 80, set. 2002. p. 136-167.

HALL, Stuart. A identidade cultural na pós-modernidade. 2 ed. Rio de Janeiro: DP\&A, 1998.

JOSSO, Marie-Cristine. Experiências de vida e formação. São Paulo: Cortez, 2004.

JOSSO, Marie-Cristine. As figuras de ligação nos relatos de formação: ligações formadoras, deformadoras e transformadoras. Educação e Pesquisa, São Paulo, v. 32, n. 2, p. 373-383, maio/ago. 2006.

KUHN, Tomas S. A estrutura das revoluções científicas. 9. ed. São Paulo: Perspectiva, 2005.

LIPOVETSKY, Gilles. O império do efêmero: a moda e seu destino nas sociedades modernas. São Paulo: Companhia das letras, 1989.

LIPOVETSKY, Gilles. Sedução, publicidade e pós-modernidade. Revista FAMECOS, Porto Alegre, n.12, p.7-9, jun. 2000.

NÓVOA, António. Os professores na virada do milênio: do excesso dos discursos à pobreza das práticas. Educação e Pesquisa, São Paulo, v. 25, n. 1, p. 11-20, jan./jun. 1999.

NÓVOA, António et al. Vida de professores. Porto: Porto Editora, 1995.

NUNES, Célia Maria Fernandes. Saberes docentes e formação de professores: um breve panorama da pesquisa brasileira. Educação \& Sociedade, Campinas, v. 22, n. 74, abr. 2001. 
PINEAU, Gaston. As histórias de vida em formação: gênese de uma corrente de pesquisa-ação-formação existencial. Educação e Pesquisa, São Paulo, v. 32, n. 2, p. 329-343, maio/ago. 2006

ROSSLER, João Henrique. As origens do poder de atração do ideário construtivista. In: DUARTE, Newton (Org.). Sobre o construtivismo. 2. ed. Campinas, SP: Autores Associados, 2005.

SANTOS, Boaventura de Souza. Pela mão de Alice: o social e o político na pós-modernidade. São Paulo: Cortez, 1996.

SILVA, Tomaz Tadeu da. Desconstruindo o construtivismo pedagógico. Educação \& Realidade, Porto Alegre, v. 18, n. 2, p. 3-10, jul./dez. 1993.

SIMMEL, G. La mode. In: . La tragédie de la culture. Paris:

Rivages, 1988.

SIMMEL, G. As grandes cidades e a vida do espírito (1903). Revista Mama, v. 11, n. 2, p. 577-591, 2005. Disponível em: <http://www. scielo.br/pdf/mana/v11n2/27459.pdf>.

TARDE, G. Les lois de l'imitation: v. I: les Empêcheurs de penser round. Paris: Editions du Seuil, 2001. (Deuxième Série)

VARGAS, Eduardo Viana. Gabriel Tarde e a emergência das ciências sociais. Rio de Janeiro: Contra Capa Livraria, 2000.

VEBLEN, Thornstein. A teoria da classe ociosa: um estudo econômico das instituições. São Paulo: Abril Cultural, 1983.

Luiz Artur Santos Cestari, doutor em Educação pela Universidade Federal de Pernambuco (UFPE), é professor adjunto da Universidade Estadual do Sudoeste da Bahia (Uesb), Itapetinga, Bahia, Brasil.

lacestari@hotmail.com

Recebido em 25 de julho de 2013.

Aprovado em 11 de março de 2014. 